\title{
The Effect of Three Kinds of Reading Strategies on EFL Learners' Reading Comprehension and Gender Difference Using Think-aloud Protocol
}

\author{
Ali Fathi Karizak \\ Department of English Language, Bandar Abbas Branch, Islamic Azad University, Bandar Abbas, Iran \\ E-mail:ali.fathi1839@yahoo.com \\ Laleh Khojasteh (Corresponding author) \\ English department, Shiraz University of Medical Sciences, Shiraz, Iran \\ E-mail: khojastehlaleh@yahoo.com
}

Received: 02-03-2016

Published: 01-09-2016
Accepted: 28-05-2016

doi:10.7575/aiac.ijalel.v.5n.5p.6
Advance Access Published: July 2016

URL: http://dx.doi.org/10.7575/aiac.ijalel.v.5n.5p.6

\begin{abstract}
Reading comprehension strategy instruction is a powerful tool in teaching context. The present study examines the effect of teaching three kinds of reading strategies on L2 learners' reading comprehension ability as well as identifying the gender role in this intervention. This quasi experimental study was carried out on 100 Iranian EFL students who were chosen on the basis of a convenient sampling procedure. These participants were divided into two groups of experimental and control. 50 students (experimental group) were taught to use three reading comprehension strategies while reading English texts over 16 sessions, whereas the other 50 students (control group) were taught reading comprehension traditionally. The results of the study revealed significant effect of reading strategies application on L2 learners' reading comprehension ability. It also showed that not only male learners employ reading strategies more than their female counterparts, but also male learners had higher reading comprehension performance in comparison to their female counterparts. Thus, it seems that training of reading strategy raised students' awareness towards these strategies and could encourage some learners to use them; which in turn could improve the students' reading comprehension skill.
\end{abstract}

Keywords: Reading; Strategy; Reading strategies; Reading comprehension; Think-aloud protocol

\section{Introduction}

To be able to read and comprehend the text can help us live and interact socially, hence according to Celce-Murcia (2001, p. 187) "not being able to either read or comprehend will result in a deep sense of detachment and uselessness". One of the most prominent academic language skills for learners' of English as a second (ESL) and foreign language (EFL) is reading. It is thought to be the primary means of gaining access to various sources of information, providing the basis for synthesis and critical skills (Celce-Murcia, 2001). The prominent role of reading for learners of English as second language (L2) has been widely recognized (Day \& Bamford, 1998, Grabe, 2004). In spite of reading process's complete nature which involves both the L2 reader's language and reading ability, utilization of reading strategies contributes greatly to one's success in reading comprehension (Bernhadt, 2005; Hudson, 2007). Bernhadt (2005) after examination of three decades of L2 reading research pointed out some criteria including readers' first language, their literacy levels, their levels of L2 knowledge and levels of interactions of vocabulary as essential tenets of contemporary in $\mathrm{L} 2$ reading.

Reading comprehension strategies allow readers to create meaning out of written texts in the most effective manner. In fact, these strategies depict the way readers deal with a reading task, comprehend a reading task and their reactions when they do not understand a reading text. Competent readers rely on background knowledge and experience to understand what they are reading; as such they use that knowledge to make associations. On the other hand, readers with difficulty go through a text without a pause. They do not consider, whether the text is sensible according to their own prior knowledge or whether this knowledge can aid them to understand perplexing or troublesome materials (Harvey \& Goudvis, 2000). Thus, readers are better able to understand what they are reading if they are taught how to associate themselves and their background knowledge with the text (Harvey \& Goudvis, 2000). Hence, it is necessary for professional teachers to usher students through the path of becoming independent and effective learners in our fastgrowing society (Baier 2005). A plan which is chosen intentionally by the reader to execute and complete a given task is called strategy (Paris, Lipson \& Wixson, 1983; Paris, Wasik, \& Turner, 1991). Students are said to have achieved independence in using the strategy, when they can chose and apply a strategy deliberately (Wells, 1990). Moreover, they will be able to use a number of comprehension and study skills together with the strategies. Reading strategy can 
be defined as "deliberate, goal directed attempts to control and modify the reader's efforts to decode text, understand words and construct meaning out of text" (Afferbach, Pearson, \& Paris, 2008, p.15).

A wide range of documents are available on the role which reading comprehension plays in language learning process (Duke, 2003). The present study and many others indicate that reading comprehension is the corner stone of learning process. As such, learners reading without comprehending the text have less chance of academic success comparing to those who read with comprehension (Krashen, 1985). There is a lack of knowledge on adequate and efficient reading comprehension interventions (Kamhi, 2005). Nowadays due to the increasing and abundance of available information, it is of vital importance to be able to read and comprehend the written texts. It is necessary for all individuals, particularly students, to have the ability of reading simple forms, interpreting advertisements, reading newspapers, and making use of initial reading strategies in their job and lives (Marzban \& Adibi, 2014).

Although in recent years an increasing number of studies have been conducted in the area of reading strategies usage and performance, there are discrepancies between the results obtained from various studies in various contexts in terms of reading performance and reading strategies use. Therefore, this study was carried out firstly because some studies confirm the fact that using reading strategies affect students' reading ability positively (Baier,2005; Koda, 2004; Grabe \& Stoller, 2002; Salataci \& Akyel, 2000), while others (e.g. McKeown, Beck \& Blake,2009) reached to the conclusion that reading strategies do not give students the necessary tool to better comprehend the reading comprehension. And secondly, few studies had been carried out to examine the real impact of instructing reading comprehension strategies on learners' reading comprehension in Iran (Khosravi, 2000). So since there is a discrepancy between the results of the above mentioned studies and still there is more to learn about the application of reading strategies among genders in Iran, it is vital to do this study to see if applying reading strategies can enhance students' reading ability.

Based on the above mentioned gaps identified in the literature, the present study aims at providing answers to the following questions:

1. Do reading strategies (skimming, scanning and locating the main idea and supporting details) have a significant impact on reading comprehension of Iranian intermediate EFL learners?

2. Is there any significant difference between male and female Iranian EFL learners in terms of their reading comprehension performance?

3. Are there any differences between males' and females' strategy use while reading expository texts?

\section{Relevant studies}

Wright and Brown (2006) examined reading strategy instruction effect in increasing the reader's awareness of reading strategies, expanding the domain of strategies implication and encouraging learners to observe and think about their reading. Result of their examination revealed that strategy training has encouraged readers to think about their strategy application and seemingly has raised their confidence level in their own reading skill. In another study conducted by Salataci and Akyel (2002), they tried to explore the possible impacts of teaching reading strategies on reading in Turkish and English languages. The findings revealed a positive impact on both Turkish and English reading texts and also on reading comprehension in English. Mikulecky and Jefferis (2004) state that when learners receive strategy instruction, they "build on their already-established cognitive abilities and background knowledge" (p.183). Students may think of reading strategies as a solution to their problems while reading which has substituted translation can increase student's confidence. As a result they may have faster access to the reading material they have to use in their academic contexts. Poole (2009) points out that "a number of studies show the connection between increased reading strategy use and skilled reading among L2 learners at the post-secondary level" (p.30).

McKeown, Beck and Blake (2009) carried out another study in which a standardized comprehension instruction for two major approaches was designed and implemented over two years. The impact of the two experimental comprehension instructional conditions, i.e. content and strategies and a control condition on learners was compared. In content instruction students' attention was on the content of the text by application of open and meaning- based questions from the text. In the other instructional condition, particular procedures were taught to students which could guide their access to text during reading of the text. At the end, outcomes of the study showed no difference between the experimental groups' performance on some aspects of comprehension.

According to Oxford and Burry-stock (1995), several researches show that females enjoy more strategies than males. Most of which were done using Oxford's strategy Inventory for language learning or SILL. The SILL is a 50 item survey designed to reveal the self-reported language learning strategies that L2 learners utilize based on Oxford and Burry-stock (1995). The SILL particularly consist of those questions which deal with six types of strategy, like cognitive strategies, affection strategies, social strategies, comprehension strategies, etc. Goh and Foong (1997) has also conducted the same research but this time the focus was on 175 Chinese L2 learners ( 50 female and125 male). They also found the same results as females used more strategies than males.

On the other hand, while majority of the studies showed that females did a better job based on applying strategies than males, other studies have found very few differences between males and females; for instance, Szoke and Sheoray (2002) conducted a comparative study of Russian and Hungarian L2 learners of English. There were Ninety-nine Hungarians students whom 32 were female and 67 were male. Russian participants were ninety-five, whom 50 were male and 45 were female. Both groups of participants were English students at the beginning, intermediate and 
advanced levels. The results of the study showed no significant difference on using strategies. Shamis (2003) has also carried out a similar study on 99 Palestinian college English students and the results showed that there were no significant overall differences between the participants. Zolfagharkhani and Kowsary (2013) conducted a study on 70 male and female pre- intermediate EFL learners, and the finding of their research indicated that gender of students did not play a significant role in reading comprehension performance. As he mentioned once females did better than males another time males did better, as a result he came to the conclusion that there is no difference on using strategies by the participants based on the results of the research.

\section{Methodology}

The following section explains the methodological procedures applied in the study.

\subsection{Design of the study}

This study employed quasi-experimental design of pretest, treatment and posttest to answer the research questions. This study is a 'quasi-experimental design' instead of an 'experimental design' because the allocation of participants was not fully randomized which is the most significant factor in determining whether the design is true experimental or quasiexperimental (Mackey \& Gass, 2005).

\subsection{Participants}

The participants in this study consisted of a convenient sample of 100 L2 learners who at the time of this study was conducted had enrolled in the language institution called Zabansara which again was chosen based on purposive sampling. It is worth mentioning that although at first the researchers used random sampling in order to choose the right language institution to conduct their study, the chosen institution did not allow the researchers to carry out this experiment. Therefore, it was decided to go for convenient sampling which allowed the researchers to choose their target population by means of easy availability or accessibility. The major disadvantage of this technique is that researchers do not have any idea how representative the information collected about the sample is to the population as a whole. However, according to Ary, Jacobs and Razavieh (2005) the information can still provide some equally significant insights.

For the third research question of this study which was qualitative in nature, 8 participants ( 4 males and 4 females) volunteered to sit in a different place than the other participants were seated in order to fulfill the requirements of thinkaloud protocol in which they had to verbalize their thoughts so that the tape recorder could record their voices.

\subsection{Instruments}

In order to gather the related data for the present study, two similar reading tests (with 4 reading texts each) for the pretest and post-test were adopted from "Select Reading" (Lee \& Gunderson, 2001) ranging from 115 to 120 words in length for each texts. The applied reading materials were expository texts which were suitable for the intermediate EFL readers. The materials were selected based on three criteria of: 1) Level of difficulty, 2) Level of interest and 3) Variety of topics based on real world issues and most important of all 4) the questions which were presented at the end of each reading text were classified into the categories which were important for this study. Since this study trained the experimental group for only three reading strategies (skimming, scanning and locating the main idea and supporting details), it was therefore important to focus mainly on these type of questions. So the given questions were mainly focusing on identifying the main idea, reading for specific information and matching the titles with the paragraph. All criteria were approved by three experts in teaching English as a foreign language major (TEFL).

In order to see whether male participants $(n=4)$ or their female counterparts $(n=4)$ (in the experimental group) use more reading strategies, think-aloud technique was chosen as another instrument for this study. Think-aloud protocol known as verbal protocol analysis is a qualitative research method by which researchers can explore subject's mental process, especially the sequence of their cognitive events (Hannu \& Pallab, 2002). This protocol is based on the assumption that when subjects under investigation verbalize their thoughts while doing certain tasks, this does not interfere with their sequence of thoughts and hence can be considered as a valid data on thinking (Ericsson \& Simon, 1984). Therefore, to see whether the male or female students use more reading strategies in both control and experimental groups, at first these 8 volunteered students were trained how to verbalize their thoughts while doing the reading test. Training was vital for such data collection (Yang, 2002) because some participants if are not trained properly might edit their thoughts to the researcher (Ericsson \& Simon, 1993) and this might affect the whole purpose of data collection. So while being trained, participants of this study learned to express their thoughts without any attempts to control, direct or observe them (Ghonsooly, 1997). Each of the participants had a tape recorder with them, so that without the interference of the researchers they could talk and record their voices.

\subsection{Data collection}

In order to make sure that no significant differences exist between control and experimental group with regard to reading comprehension ability, a pre-test was administrated, and the mean of the pre-test was calculated. As it can be seen in the following table, control group's mean score before treatment was 12.83 while for experiment group, it was 13.06. Despite the fact that experimental group's mean score is a little above of the control group, t-test demonstrated that this distinction is not significant. Because, $\mathrm{P}$ value is higher than $0.05(\mathrm{P}=.112>0.05)$. Consequently, both groups were homogenous with regard to their reading comprehension ability. 
Table 1. The mean of pre-test scores of two groups

\begin{tabular}{cccccc}
\hline Groups & $\mathrm{N}$ & Mean & SD & $\mathrm{T}$ & Sig. \\
\hline Control & 50 & 12.83 & 1.68 & -619 & .112 \\
\hline Experiment & 50 & 13.06 & 2.01 & & \\
\hline
\end{tabular}

Then, after fifteen sessions of treatment program, all participants in both groups participated in the post-test. The posttest was similar to the test which had been administrated as the pre-test.

\subsection{Data Analysis}

For the first research question, in order to determine if mean scores of the experimental and control group were reliably different from one another after the given treatment, independent sample t-test was applied. Similarly, in order to see if any significant difference exist between Iranian male and female EFL learners regarding their reading comprehension ability, independent sample t-test was administered. And for the third research question (to see if male or female participants in the experimental group use more reading strategies), a qualitative research method was adopted to analyze the transcription of participants' verbalized thoughts (Cullum, 1998). But it is worth mentioning that after the transcription of the tapes was over, one of the authors of this study divided the participants' utterances into "communication units" which were equivalent to grammatical sentences (Pressley \& Afflerbach, 1995, p. 65). This is important with think-aloud protocol method because in this type there might be many false starts, overlaps and incomplete sentences in the utterance of the participants that might be misguiding to the whole data analysis. Hence, in this classification, "minimal terminable unit" of meaning or "T unit" was considered as a unit which was going to be used for this data analysis (Cooper, 1999, p. 242). Then all these units were coded to find the reading strategies that were used more frequently by the participants of this study. It is important to note that, although this method is considered useful, according to Johnson (1992, p. 71), it is "limited because of the small sample size".

It is also worth mentioning that, although Nunan, (1999) listed 9 major reading strategies, this study only focused on three reading strategies, skimming, scanning and locating the main idea, which were taught to the experimental group in the treatment.

\section{Findings}

The first research question of the study was 'Does learning reading strategies affect Iranian EFL learners' reading performance?" As it is shown in Table 2, experimental group (Mean=15.73) performed better than control group (Mean=13.00) after receiving the treatment. The difference between two groups is significant because $\mathrm{P}<0.05$ $(.000<.05)$. This finding verifies the fact that reading strategies instruction can make learners aware of these strategies and probably make them more capable in reading comprehension. So, instruction of these strategies was proved to have a significant positive effect on students' reading comprehension.

Table 2. T-test for mean differences after treatment (post-test)

\begin{tabular}{ccccccc}
\hline Groups & Mean & SD & F & T & DF & Sig. \\
\hline Control & 13.00 & 1.52 & 6.34 & -8.162 & 49 & .000 \\
\hline Experiment & 15.73 & 1.80 & & & & \\
\hline
\end{tabular}

The second research question of this research was "Is there any significant difference between male and female Iranian EFL learners who applied reading strategies in terms of their reading comprehension performance?" In order to find the answer to this question a t-test was administered and the results can be seen in Table 3 .

Table 3. The difference between the performance of the male and female learners

\begin{tabular}{ccccccc}
\hline Gender & $\mathrm{N}$ & Mean & Std. Deviation & Std. Error Mean & $\mathrm{t}$ & $\mathrm{sig}$ \\
\hline Male & 23 & 13.700 & 1.5138 & .3027 & 3.615 & .001 \\
& & & & & & \\
\hline Female & 27 & 12.300 & 1.2076 & .2415 & 3.615 & \\
\hline
\end{tabular}

Observing the significance level of the distinction between the female and male students' performance, it can be seen that the distinction was statistically significant $(.001<.05)$. In other words, the mean gained from males' performance is more than that of females' performance. Thus, it is evident that the male group has outperformed the female one in terms of reading comprehension performance. 
To answer the third research question (Are there any differences between males' and females' strategy use while reading expository texts?), a qualitative approach was adopted and the results are explained in the following.

As it can be seen in the following table, the result shows that men used more reading strategies (skimming, scanning and locating the main idea and supporting details) than their female counterparts.

Table 4. The frequency and percentage of strategies use by male and female participants

\begin{tabular}{lcccc}
\hline & \multicolumn{2}{c}{ males } & \multicolumn{2}{c}{ females } \\
\hline Reading strategies & frequency & percentage & frequency & percentage \\
\hline skimming & 4 & $10.8 \%$ & 2 & $6.6 \%$ \\
\hline scanning & 19 & $51 \%$ & 17 & $56 \%$ \\
\hline $\begin{array}{l}\text { locating the main idea and } \\
\text { supporting details }\end{array}$ & 14 & $37 \%$ & 11 & $36 \%$ \\
\hline total & 37 & $100 \%$ & 30 & $100 \%$ \\
\hline
\end{tabular}

Out of four male participants, all of them (100\%) reported that they read the title of the reading passage first and then underlined the keywords and then started reading the first sentences of each paragraph very fast and underlined the key words in those sentences. The following are representative comments for the male participants- "First I need to understand what the topic is, so [...] I underline this word here "Tamar Blackmore" because it is capital and might be important, then I also underline this word "culture shock" because I guess this passage is about this person and how he experienced culture shock". This result is somehow different with female participants because 2 out of 4 of them reported jumping to questions first without even skimming the passage (or at least this is what we could be interpreted from their utterances and considering the short time slot after the recording had begun). However, these two female participants reported that they too looked for main key words in the question part and underlined the keywords in the each multiple choices provided after each question. It is only after reading the questions that they (only 2 female participants) started to mix the skimming and scanning strategies together and looked for the answers (scanning) or sometimes skimming (read through the text fast) to be able to answer the questions. This attitude is a bit surprising to the researchers of this study, because the researcher who conducted these classes and trained these learners (in the experimental group) recalls telling all the students in the class to always start reading the topic and skimming through the text for a minute in order to get a general overview of what the text/passage is all about. And this shows how learners, despite having practiced this for few weeks, can get back to their old habits perhaps when under pressure and stressed.

The other two female participants; however, reported looking at the topic first and skimming through the text in order to collect important information from the whole text. The representative comment from one of the above mentioned female participants is "after knowing the topic, I need to know what the main idea of the text is, so I will read the first line of all the paragraphs (then she started reading the first line), ok I underline this word (drive) because I think these are important, then father, allow, movies and angry. So I guess the whole passage can be summarized like this:
a) wanting to drive so badly
b) father gave him permission
c) losing track of time because of watching a movie
d) father got angry"

All in all out of the three strategies taught to the participants of this study, scanning was the most used strategy by all the participants (male and female participants), followed by locating the main idea and supporting details (both in the text and for the questions) and skimming.

It is also worth mentioning that all the participants used various other types of strategies such as inferencing, skipping, repetition and translation to answer all the reading comprehension questions in the test. However, since this study only focused on three reading strategies, skimming, scanning and locating the main idea and supporting details, the results are only limited to these reading strategies.

\section{Discussion}

Question one asked: Do reading strategies have a significant impact on reading comprehension skill of Iranian intermediate EFL learners? This question was posed with the purpose of finding out whether reading strategies instruction can have any effect on EFL learners' reading comprehension skill. According to the results of the analysis shown in Table 2, the answer is positive. Instruction of reading strategies can affect EFL learners' reading skills adequately and significantly improve students' reading ability. The finding of this part of the study are consistent with studies conducted by Wright and Brown (2006), Baier (2005), Koda (2004), Grabe and Stoller (2002), Salataci and Akyel (2000), Harvey and Goudvis (2000), Kern (1989), Hamp-Lyons (1985), in which the researchers also found a significant relationship between employment of reading strategies and reading comprehension improvement. 
Furthermore, some other studies even found that vocabulary learning strategies positively affect reading comprehension (Kafipour and Naveh, 2011). However, the findings of the current study are not in line with the results of studies carried out by Shong (2010), Mckeown, Beck and Blake (2009), Soleimani and Hajghani (2013). These studies showed no effect on EFL learners' comprehension ability after using reading strategies while the current study found that strategy instruction significantly improve EFL learners reading comprehension ability. The discrepancies found here between the results provided above might possibly be due to the fact that the students who were the participants of this study were in the intermediate level and according to Hong-Nam and Leavell (2006), intermediate level students use more of learning strategies in comparison with beginning and advanced students and hence more strategic learners achieve more in the proficiency continuum than their beginning and advanced level counterparts. The theory about the link between proficiency level of the learners and the impact it can have on learners' strategy adoption has been backed up by other researchers such as Yau (2005) and YaaliJahromi (2002). Another reason for why the results of the above mentioned studies differ might be due to the strategy instruction. According to Caposey and Heider (2003) reading strategy instructions can be effective only when they are intensive, explicit, and most important of all persistent. That is why Poole (2005) reported that reading strategies that focuses on boosting comprehension is less frequently explicitly taught by teachers and more emphasis is usually given to literacy skills such as decoding and phonological awareness.

The second research question was posed in order to figure out the gender distinction among Iranian EFL learners in terms of reading comprehension performance. As previously reported, the mean of male performance is higher than the mean of female performance. So, probably because of using more strategies, male participants did better in their reading comprehension test than their female counterparts. The result of this study is line with another study conducted by Phakiti (2003). This study focused on 173 male and 211 female Thai college students and the results showed that male participants outperformed female participants in terms of cognitive and metacognitive strategies utilization. However, This result is in contrast with the study which was conducted by Keshavarz and Ashtarian (2008) who reported that in general, regardless of the type of the text (e.g. essay, history, and short story), women are better comprehenders than men. The result of this study is not also in line with another study carried out by Yazdanpanah (2007) who reported that there is no significant difference between the overall performance of males and females in terms of reading comprehension performance. However, this study also reported that in general women did better in identifying the main idea, guessing meaning from context, and text coherence questions while men outperformed women in males' outperformed females in reading for specific information, identifying referential information, and matching titles with paragraph. The result of this study is also in contrast which another study conducted by Mehrpour, Razmjoo and Kian (2011) who reported that gender had no significant impact on learners' reading comprehension performance. As it can be seen here, again the result obtained by this study is at odd with few other studies mentioned above. Although it is very important to be cautious while approaching the area of gender and reading strategy use, one possibility might be due to the level of the proficiency learners in each study might have that have led to various results obtained by these studies. For example, in the study which was conducted by Poole (2005), the result showed that reading strategy usage was not very much influenced by gender for advanced level learners. Likewise, in another study conducted by Sheorey and Mokhtari (2001), the results showed that there is not a significant difference between 152 ESL advanced level students in terms of reading strategy usage. So we can see that while studying the relationship between gender and reading strategy, the role of learners' proficiency level should be carefully documented because according to Poole (2005, p. 17), "whatever gender differences that exist at lower proficiency levels could be largely neutralized for advanced students."

The result of the third research question showed that males used more strategies than females. The results of this research question is at odds with the previous study research conducted by Poole (2009) who found that women make more use of reading strategies comparing to men, or Sheorey and Mokhtari (2001) who believed that there is no difference between males and females in the use of reading strategy. Similarly, Kafipour, Noordin and Pezeshkian (2010) in another study but on language learning strategies found no significant difference between males and females learners in the application of these strategies. In fact, Oxford (1993) suggests that females tend to be higher L2 achievers because of their higher level of strategy use and not because of any innate gender differences.

\section{Conclusion}

As it can be seen here, the majority of the studies chosen for the discussion section here had been conducted in the same country, Iran, but the results showed a great degree of inconsistency. There are some studies that show no significant difference between males and females in terms of reading performance and the usage of reading strategies while some others showed that women do better both in terms of reading strategies usage and reading comprehension performance. Some also, like this study, showed that male participants outperform their female counterparts in the former and the latter. This deep inconsistency between the results, according to the authors of this study, might have one key reason and that is the type and the degree of the familiarity of male and female participants towards the given texts. This, in turn, can have a major contribution to how they (males or females) approach the reading text and how they perform the reading questions. According to Brantmeier (2001), the content of a passage is related to one's achievement in reading. As he stated, men outperform on more science-oriented texts while women gain higher reading scores on subjects related to humanities. Apparently, such results are associated with one's perception of one's interests and might involve utilization of different strategies. Sotoudehnama and Asadian (2011) also reported that in the study they had done on test type on reading comprehension, the female participants did better in female-oriented text, men did better on maleoriented text and both genders performed the same when they were dealing with neutral text. So we can conclude that unless all these studies come from the same nature, similar text type and similar gender-oriented texts, we cannot really 
say whether male or female participants are better in reading comprehension performance or even reading strategies. Poole (2005) also believe that advanced ESL readers' strategies are primarily influenced by factors other than gender. So, it is strongly suggested that in order to assess learners' reading strategies, researchers must disregard passages that has preconceptions suitable for one gender or the other. This is, in fact, one of the limitations of this study because except focusing on the genre of the reading text for both pre- and post- tests, the researchers of this study did not take into consideration whether the texts chosen were neutral in general. And now analyzing whether those texts were more male-oriented or female-oriented is out of the scope of this study. Another limitation of this study is that this study only included some of the students in one private language center, who had to pass their reading course, and this research may not be generalized to the other language centers, schools and university students in other contexts.

\section{References}

Alderson, J.C. (1984). Reading in a foreign language: A reading problem or a Language Problem? In J. C. Alderson and A. H. Urquahart (Eds.). 1984: Reading in a foreign Language. London: Longman.

Ary, D., Jacobs, L.C. \& Razavieh, A. (2005). Introduction to research in education, 7th edition. Wadsworth / Thomson Learning, California.

Baier, J. R. (2005). Reading comprehension and reading strategies. Published dissertation. Master of Education Degree in Education. The Graduate School: University of Wisconsin-Stout.

Bernhardt, E.B. (2005). Progress and procrastination in second-language reading. In Mary McGroarty (Ed). Annual Review of Applied Linguistics. (pp. 133-150). Cambridge: CUP.

Brantmeier, C. (2001). Second language reading research on passage content and gender. Challenges for the intermediate level curriculum. Foreign language Annals, 34, 325-333.

Caposey, T., \& Heider, B. (2003). Improving reading comprehension through cooperative learning. Unpublished

dissertation. St. Xavier University \& Pearson/Skylight, Chicago, IL. Celce-Murcia, M. (2001). Teaching English as a second or foreign language. Boston: Heinle \& Heinle, Thomson learning, Inc.

Cooper, J. D. (1999). Literacy: Helping children construct meaning. Boston, MA: Houghton Mifflin.

Cullum, L. (1998). Encouraging the reluctant reader: Using a Think-aloud Protocol to Discover Strategies for Reading Success. ERIC Document No. ED420 837.

Davis, S. (2010). A meta-analysis of comprehension strategy instruction for upper elementary and middle school students. Unpublished PHD, dissertation. Vanderbilt University, America.

Day, R. R. \& Bamford, J. (1998). Extensive reading in the second language classroom. In Cambridge language education (J.C. Richards, Ed.) Cambridge: Cambridge university press.

Duke, N. (2003, March 7). Comprehension instruction for informational text. Presentation at the annual meeting of the Michigan Reading Association, Grand Rapids, MI.

Ericsson, K., \& Simon, H.J. (1993). Protocol analysis: Verbal reports as data. Cambridge, MA: MIT Press.

Ghonsooly, B. (1997). Introspection as a method of identifying and describing competence in reading skills, Doctoral dissertation, University of Stirling, UK.

Goh, C., \& Foong, K. (1997). Chinese ESL students' learning strategies: A look at frequency, Proficiency, and gender. Hong Kong Journal of Applied Linguistics, 2(1), 39-53.

Grabe, W. \& Stoller, F. L. (2002). Teaching and Researching Reading. Harlow: Longman.

Grabe, W. (2004). Research on teaching reading. Annual Review of Applied Linguistics, 24, 44-69.

Hamp-Lyons, L. (1985). Two approaches to teaching reading: A classroom-based study. Reading in a Foreign Language, 3, 363- 373.

Hannu, K. \& Pallab, P. (2002). A comparison of concurrent and retrospective verbal protocol analysis. American Journal of Psychology, 11-18, 387-404.

Harvey S. \& Goudris, A. (2000). Strategies that Work: Teaching Comprehension to enhance. Understanding: Portland, M.E. Stenhouse.

Hong-Nam. K, Leavell. AG. (2007). A Comparative study of language learning strategy use in an EFL context: Monolingual Korean and bilingual Korean-Chinese University students. Asia Pacific Education Review, 8(1), 71-88.

Hudson, T. (2007). Teaching second language reading. Oxford, England: Oxford University Press.

Johnson, k. E. (1992). The relationship between teacher's beliefs and practices during literacy instruction for non-native speakers of English. Journal of reading behavior, 24(1), 83-108.

Kafipour, R. \& Naveh, M. H. (2011). Vocabulary learning strategies and their contribution to reading comprehension of EFL undergraduate students in Kerman province. European Journal of Social Sciences, 23(4), 626-647. 
Kafipour, R., Noordin, N. \& Pezeshkian, F. (2010). Effects of motivation and gender on the choice of language learning strategies by Iranian postgraduate students. Pertanika Journal of Social Sciences and Humanities, 19(1), 159-171.

Kamhi , A.G. (2005). Finding beauty in the ugly facts about reading comprehension. In H. W. Catts, \& A. G. Kamhi (Eds.), The connection between language and reading disabilities (pp.201-212). New Jersy: Lawrence Erlbaum Associates.

Kern, R. (1989). Second language reading strategies instruction: its effects on comprehension and word inference ability. Modern language Journal, 73, 135-49.

Keshavarz. M.H \& Ashtarian, S. (2008). The Relationship between Iranian EFL Learners' Gender and Reading Comprehension of Three Different Types of Text. Iranian journal of applied linguistics, 11(1), 97-114.

Krashen, S.D. (1985). The input hypothesis. London: Longman.

Khosravi, A. (2000). The effect of scanning and skimming on the rate of and reading Comprehension of Iranian EFL learners. Master thesis Shiraz University, Iran.

Koda, K. (2004). Insight in to second language. Across-linguistic approach. Cambridge: Cambridge university press.

Lee, L \& Gundersen, E. (2001). Select Readings: Intermediate. Oxford university press.

Mackey, A. \& Gass, S, M. (2005). Second language research: Methodology and design. Mahwah, NJ: Lawrence Erlbaum Associates.

McKeown, M. Beck, I. and Blake, R. (2009). Rethinking reading comprehension instruction: A comparison of instruction for strategies and content approaches, Reading Research Quarterly, 44(3), 218-253.

Marzban, A. \& Adibi, A. (2014). The effect of teaching paragraph structure rules on Iranian intermediate EFL learners' reading comprehension ability. Theory and Practice in Language Studies, 4(2), 387-394.

Mehrpour, S., Razmjoo, S. A., \& Kian, P. (2011). The relationship between depth and breadth of vocabulary knowledge and reading comprehension among Iranian EFL learners. Journal of English language teaching and learning, 53(222), 97-127.

Mikulecky, B. and Jeffries, L. (2004). More Reading Power. New York: Pearson.

Nunan, D. (1999). Second language teaching and learning. Boston, MA: Heinle \& Heinle.

Oxford, R. L. (1993) Instructional implication of gender differences in second /foreign language (L2) learning styles and strategies. Applied language learning, 4(182), 65-94.

Oxford, R. L., \& Burry- Stock, J. A. (1995). Assessing the use of language learning strategies worldwide with the ESL/EFL version of the strategy Inventory for language learning (SILL). System, 23, 1-23.

Paris, S. Wasik, B. \& Turner, J. (1991). The development of strategic readers. In P.D. Pearson, R. Barr, M.L. Kamil\& P. Mosenthal. (eds.). Handbook of reading research (1), (pp.609-640). New York: Longman.

Paris, S. G. Lipson, M.Y. \& Wixon, K. K. (1983). Becoming a strategic reader. Contemporary Educational Psychology, 8, 293-316.

Poole, A. (2009). The reading strategies used by male and female Colombian university students. Issues in teachers' professional Development, 11(1), 29-40.

Poole, A. (2005). Gender and academic reading strategies: A survey of adult EFL learners in Mainland China. Hong Kong Journal of Applied Linguistics, 10(2), 38-51.

Phakiti, A. (2003). A closer look at gender and strategy use in L2 reading. Language Learning, 53, 649-702.

Pressely, M., \& Afflerbach, P. (1995). Verbal protocols of reading: The nature of constructively responsive reading, Hillsdale, NJ: Lawrence Erlbaum Associates Inc.

Salataci, R. \& Akyel, A. (2002). Possible effects of strategy instruction onL1 and L2 reading. Reading in a foreign language, 14 (1). 234-255.

Shamis, W. A. (2003) Language learning strategy use in Palestine. TESL-EJ, 7(2), 20-33.

Shang, Hai-Fang(2010). Reading Strategy Use, self-efficacy and EFL reading comprehension. Asian EFL Journal, 12(2), 18-42.

Sheorey, R. \& Mokhtari, K. (2001). Differences in the metacognitive awareness of reading strategies among native and non-native readers.

Soleimani, H. \& Hajghani, S. (2013). The effect of teaching reading comprehension strategy on Iranian EFL, preuniversity students' reading comprehension ability. International journal of Payame Noor University of Iran.

Sotoudehnama, E., \& Asadian, M, (2011). The effect of gender oriented content familiarity and test type on reading comprehension. The journal of teaching language skills, 3(2), 155-179.

Szoke, E. \& Sheorey, R. (2002). A comparative study of the learning strategies of Hungarian and Russian college Students. Novelty, 9(3), 23-36.

Wells, G. (1990). Talk about text: where literacy is learned and taught. Curriculum Inquiry, 20(4), 369-405. 
Wright, M. \& Brown, P. (2006). Reading in a modern foreign language: exploring the potential benefits of reading strategy instruction. Language learning journal, 33, 22-23.

YaaliJahromi. A. (2002). The relationship between Iranian EFL learners' sex, and level of proficiency, and their reading comprehension strategy use. MA. Thesis, Shiraz Azad University.

Yang, Y. (2002).Reassessing Reader's Comprehension Monitoring. Reading in a Foreign Language, 14(1), 18-42.

Yau. JC. (2005). Two Mandarin readers in Taiwan: Characteristics of children with higher and lower reading proficiency levels. Journal of Research in Reading, 28(2), 108-123.

Yazdanpanah, Kh. (2007). The effect of background knowledge and reading comprehension test items on male and female performance. The Reading Matrix, 7(2), 64-80.

Zolfagharkhani, M. \& Kowsary, M. A. (2013). The Relationship between Reading Aloud Strategies and Comprehension Among the Iranian EFL learners in Pre-Intermediate Levels, Studies in Literature and Language, 6(1), 74-77. 